\title{
Prognosis of patients with primary malignant main stem bronchial tumors: 7,4I8 cases based on the SEER database
}

This article was published in the following Dove Press journal: OncoTargets and Therapy

Ke Ma*
Fenghao Sun*
Xiaodong Yang
Shuai Wang
Lin Wang
Yulin Jin
Yu Shi
Wei Jiang
Cheng Zhan
Qun Wang
Department of Thoracic Surgery,
Zhongshan Hospital of Fudan
University, Shanghai, People's Republic
of China
*These authors contributed equally
to this work
to this work
Correspondence: Cheng Zhan;

Qun Wang

Department of Thoracic Surgery,

Zhongshan Hospital of Fudan University,

No 180, Fenglin Road, Shanghai 200032

People's Republic of China

Tel/fax +86 2I 64041990

Email czhan10@fudan.edu.cn;

wang.qun@zs-hospital.sh.cn
Background: The aim of this study was to identify risk factors for patients with malignant main stem bronchial tumors (MBTs) and to develop a nomogram for predicting prognosis in those patients using data from the Surveillance, Epidemiology, and End Results (SEER) database.

Method: A process was used for case screening from the SEER database. The effect of prognostic factors on survival was evaluated using the Kaplan-Meier method and log-rank test, a competing risk model, and the Cox proportional hazards regression model. A nomogram was established for predicting 1-, 3-, and 5-year overall survival (OS) in patients with MBTs.

Results: A total of 7,418 cases were included in this study. Age, gender, pathologic grade, histologic type, tumor size, involvement of lymph nodes, tumor extension, chemotherapy, and surgery were identified as independent risk factors by univariate and multivariate analyses. A nomogram was established based on the results of the Cox model, which was validated by a C-index of 0.672 (95\% CI, 0.664-0.680), and a group of calibration plots.

Conclusion: Age, gender, pathologic grade, histologic type, tumor size, involvement of lymph nodes, tumor extension, chemotherapy, and surgery were independent risk factors for OS of patients with MBTs. A nomogram was formulated to predict 1-, 3-, and 5-year OS in patients with MBTs based on individual clinical characteristics.

Keywords: malignant main stem bronchial tumor, nomogram, prognosis, risk factors

\section{Introduction}

Malignant main stem bronchial tumors (MBTs) are a group of extremely rare neoplasms situated in large airways between the carina and hilum of the lung, which represents $<0.6 \%$ of pulmonary tumors. ${ }^{1}$ A number of MBTs are misdiagnosed as asthma or chronic obstructive pulmonary disease in the early stages due to negative chest $\mathrm{X}$-ray findings and nonspecific symptoms caused by airway obstruction or secondary pulmonary infections. ${ }^{2,3}$ With the development of flexible bronchoscopy, there has been an increase in the diagnosis of MBTs. ${ }^{4}$ Surgery, radiotherapy, and chemotherapy are the main treatment strategies for MBTs; ${ }^{2,5,6}$ however, because of the rarity of MBTs, there is little experience targeting factors influencing prognosis based on large samples, and guidelines for the TNM staging system have not been provided. Thus, it is necessary to precisely predict prognosis when selecting a therapeutic strategy of MBTs.

Nomography, a statistic-based tool to quantify risk by incorporating and illustrating clinical factors of a tumor, has been widely used to predict survival of cancer patients..$^{7-10}$ Nomograms have been shown to have good accuracy and have even been proposed as a new standard. ${ }^{11}$ The advantage of nomography, including visual and quantifiable features, makes nomography user friendly for physicians and patients. Therefore, in 
this study, we used nomograms along with univariate and Cox hazards regression analyses to identify risk factors affecting overall survival (OS) of MBTs and develop a nomogram to predict the prognosis for MBTs patients based on the data derived from the Surveillance, Epidemiology, and End Results (SEER) database.

\section{Patients and methods}

\section{Study population}

The data used in this study were retrieved from the SEER database (http://seer.cancer.gov/), which is freely available to the public. The SEER program of the National Cancer Institute is an authoritative source of information on cancer incidence, prevalence, mortality, population-based variables, primary tumor characteristics, and treatment, and covers approximately $28 \%$ of the US population. ${ }^{12}$

SEER * Stat software was used to examine the target population from the data between 1973 and 2014. Patients with the following criteria were included in this study: the primary tumor site was the main stem bronchus, and the follow-up survival months had complete dates, and there was $>0$ day of survival. The following information was collected for each patient from the SEER database: the demographics of patients (age at diagnosis, gender, and race/ethnicity); characteristics of tumors (tumor size, involvement of lymph nodes, tumor extension, pathologic grade, and histologic type); therapy details (surgery, radiotherapy, and chemotherapy); and follow-up records (cause of death, cancer-specific death, and survival months). Patients missing the aforementioned data were excluded.

\section{Characteristics of patients}

For further analysis, some variables were divided into different subgroups. The histologic types of tumors were categorized into five groups, including squamous cell carcinoma (SQCC), adenocarcinoma (AC), large-cell carcinoma (LCC), small-cell carcinoma (SMCC), and others (sarcoma, adenosquamous cancer, and other types not categorized as above). Involvement of lymph nodes were divided into three grades (no involvement, involvement of local lymph nodes [ipsilateral nodes of bronchi, hilus of the lung, pulmonary ligament, intrapulmonary nodes, aortic nodes, carinal nodes, pericardial nodes, peri-/paraesophageal nodes, and peri-/paratracheal nodes], and involvement of distant nodes [supraclavicular nodes, contralateral nodes of the hilus, mediastinum, and bronchopulmonary nodes]). With respect to the level of tumor extension, distant extension includes pleural effusion, contralateral lung and main stem bronchi, pericardium, trachea, esophagus, pulmonary ligament, pulmonary artery or vein, azygos vein, aorta and vena cava, chest wall, diaphragm, or other organs beyond the thoracic cavity.

\section{Statistical analysis}

Survival curves for each variable were evaluated using the Kaplan-Meier method and were compared using the log-rank test. Variables in which the significance of probability $(P)$ value was $<0.05$ were used in multivariate analysis performed using the Cox proportional hazards regression model. Statistical analyses to identify independent prognostic factors were performed using SPSS 24.0 (IBM Corp., Armonk, NY, USA) for Windows.

The cumulative incidence function (CIF) of MBT-specific deaths based on the competing risk model was used as a validation of univariate analysis. ${ }^{13}$ Other causes of death were competing events for MBT-specific deaths in the model. Gray test, a special test for the competing risk model, was used for evaluation, in which a $P$-value $<0.05$ was considered to have statistical significance.

A nomogram on the basis of the results of multivariate analysis was formulated using the survival and rms package in R 3.4.0 (http://www.r-project.org). The strength of rank correlation between the predicted probability and actual responses of the nomogram was measured by calculating the concordance index (C-index). The $\mathrm{C}$-index ranges from 0.5 to 1.0 and a larger $\mathrm{C}$-index indicates better accuracy for predicting prognosis. ${ }^{14}$ The calibration plot based on bootstrap resampling validation of the nomogram was performed by comparing the predicted survival with the observed survival. In addition, competing risks analysis was performed using the function of CumIncidence. $\mathrm{R}$ based on the cmprsk $\mathrm{R}$ package. ${ }^{15}$

\section{Results}

The proportion of MBTs among all pulmonary tumors is approximately $4.9 \%(4.94 \mathrm{~K} / 1.04 \mathrm{M})$ in the SEER database. A group of 49,368 patients with MBTs were identified; patients with missing records or exact data on any of the abovementioned examined variables were excluded. The selection process is shown in Figure 1. Thus, a total of 7,418 patients were included in the current study.

\section{Survival analysis}

Of the 7,418 patients in the current study, the median follow-up time was 10 months (range, 4-22 months) and the overall 5 -year survival rate was $11.9 \%(95 \%$ CI, 11.1\%-12.7\%). The OS curve is shown in Figure 2. 


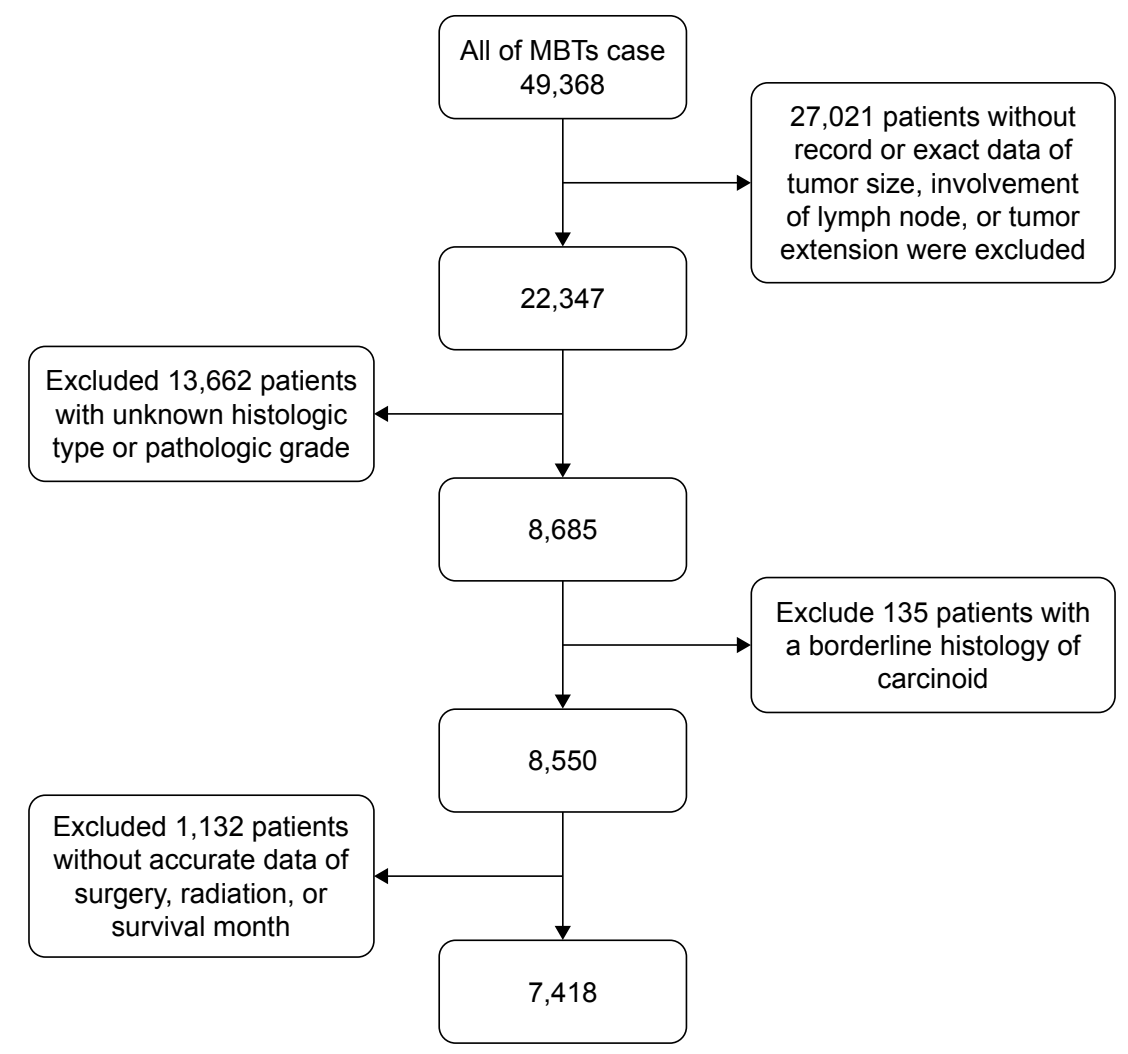

Figure I The flow diagram of the selection process for the study. Abbreviation: MBTs, malignant main stem bronchial tumors.

The results of univariate analysis are displayed as Kaplan-Meier curves. As shown in Figure 3, among the demographic data younger age $(P<0.001$, Figure $3 \mathrm{~A})$ and female gender $(P=0.047$, Figure $3 \mathrm{~B})$ were associated with
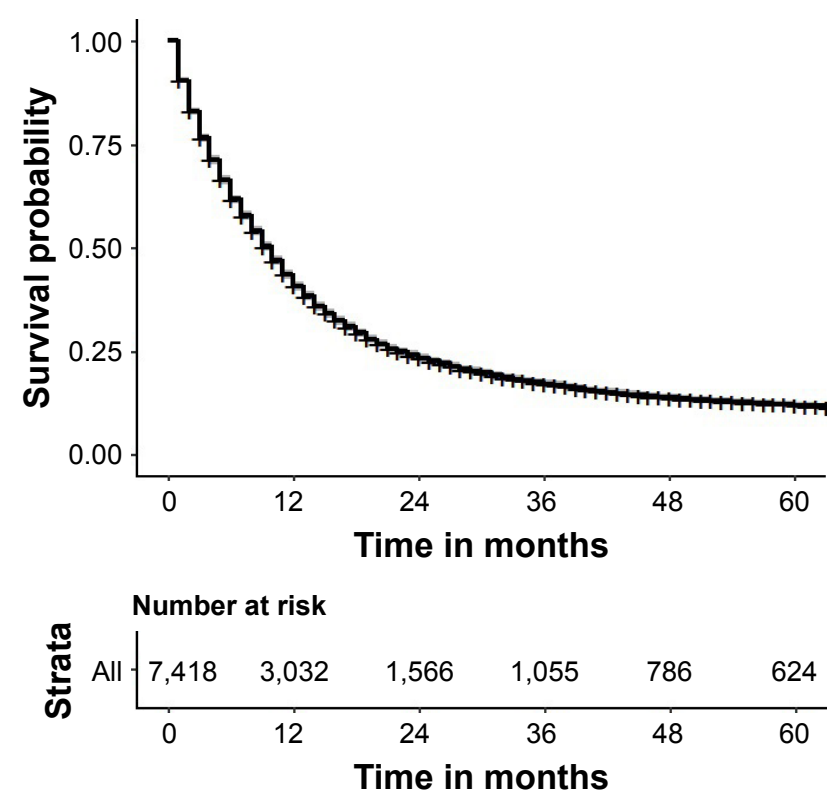

Figure 2 Overall Kaplan-Meier survival curve of all included patients. better prognosis, but there was no statistically significant difference as a function of race $(P=0.400$, Figure $3 \mathrm{C})$.

The correlation between the characteristics of MBTs and prognosis is shown in Figure 4. Survival outcome differed with histologic type $(P<0.001$, Figure 4A). SMCC, LCC, and $\mathrm{AC}$ had a similar 5-year survival rate, which was worse than SQCC and other types. Furthermore, when assessing pathologic grade, it was also shown that better differentiation was associated with more favorable survival $(P<0.001$, Figure 4B). In addition, larger tumor size $(P<0.001$, Figure 4C), involvement of lymph nodes $(P<0.001$, Figure 4D), and distant extension $(P<0.001$, Figure 4E) were also independent risk factors in prognosis of MBT.

As shown in Figure 5, patients who underwent surgery $(P<0.001$, Figure 5A) and chemotherapy $(P<0.001$, Figure 5B) had significantly better survival, while radiotherapy was not a risk factor ( $P=0.690$, Figure $5 C$ ). Radiotherapy, however, had a different effect which depended on whether or not patients had undergone surgery. Radiotherapy had an unfavorable influence for surgery patients, but showed an association with better prognosis in patients without surgery. The details of the correlation between survival and factors mentioned above are shown in Table 1. 


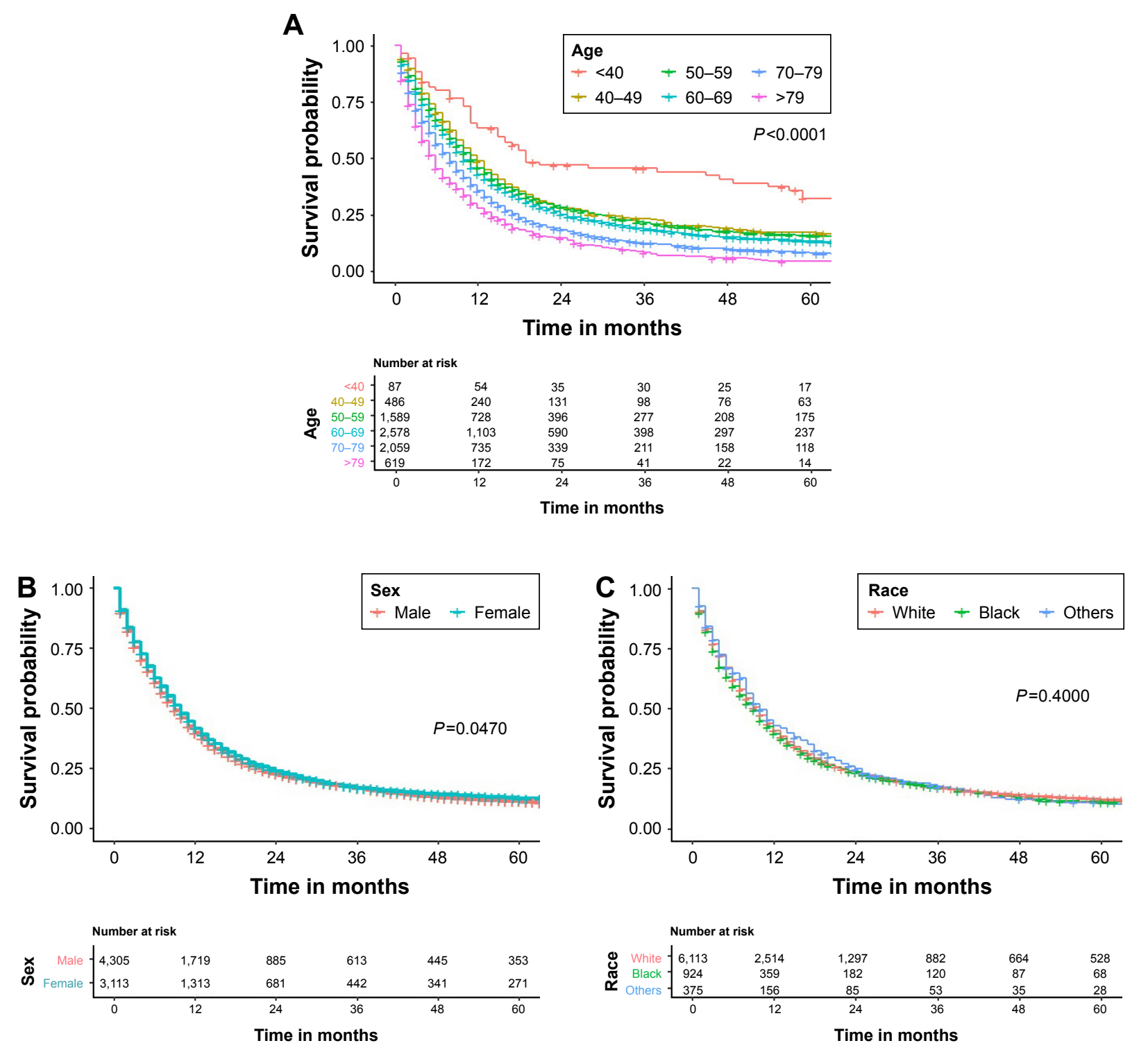

Figure 3 Overall Kaplan-Meier survival curve for patients according to $(\mathbf{A})$ age, $(\mathbf{B})$ gender, and $(\mathbf{C})$ race.

The CIF of MBT-specific death based on the competing risk model are listed in Table S1, and showed a consistent result compared to univariate analysis.

All significant risk factors in univariate analysis were applied to multivariate analysis. The results of Cox hazards regression analyses are listed in Table 2 and showed that age $(P<0.001)$, gender $(P<0.001)$, pathologic grade $(P<0.001)$, histologic type $(P=0.001)$, surgery $(P<0.001)$, tumor size $(P<0.001)$, involvement of lymph nodes $(P<0.001)$, and tumor extension $(P<0.001)$ remained independent risk factors in the Cox model.

The nomogram, which incorporated independent significant risk factors based on the Cox model and included all 7,418 patients, is shown in Figure 6. It is a convenient process to predict 1-, 3-, or 5-year OS by the nomogram. We first needed to collect all information of risk factors in the nomogram of the patient, and then we assigned a score for each predictor according to the upper scale, and summed these scores to get an event probability by referring to the bottom three score scale. The nomogram had a C-index of 0.672 (95\% CI, 0.664-0.680), showing good predictive ability. The calibration plots based on bootstrap resampling validation is illustrated in Figure 7, and showed good agreement with the reality of observation for 1-, 3-, and 5-year OS.

\section{Discussion}

Primary MBTs are rare and represent approximately 4.9\% of pulmonary tumors in the SEER database, which is higher 

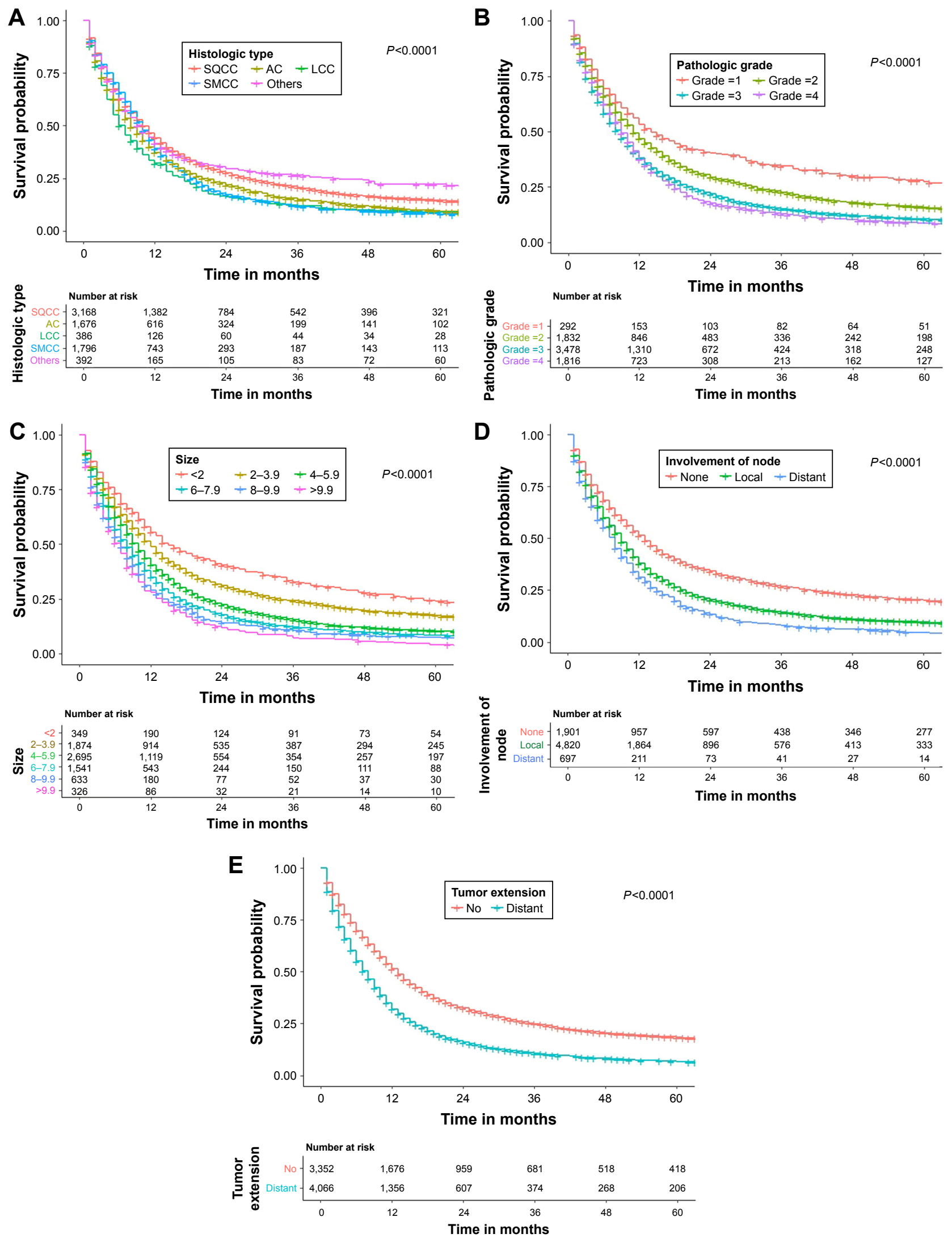

Figure 4 Overall Kaplan-Meier survival curve for patients according to (A) histologic type, (B) pathologic grade, (C) tumor size, (D) involvement of lymph node, and (E) tumor extension.

Abbreviations: SQCC, squamous cell carcinoma; AC, adenocarcinoma; LCC, large-cell carcinoma; SMCC, small-cell carcinoma. 

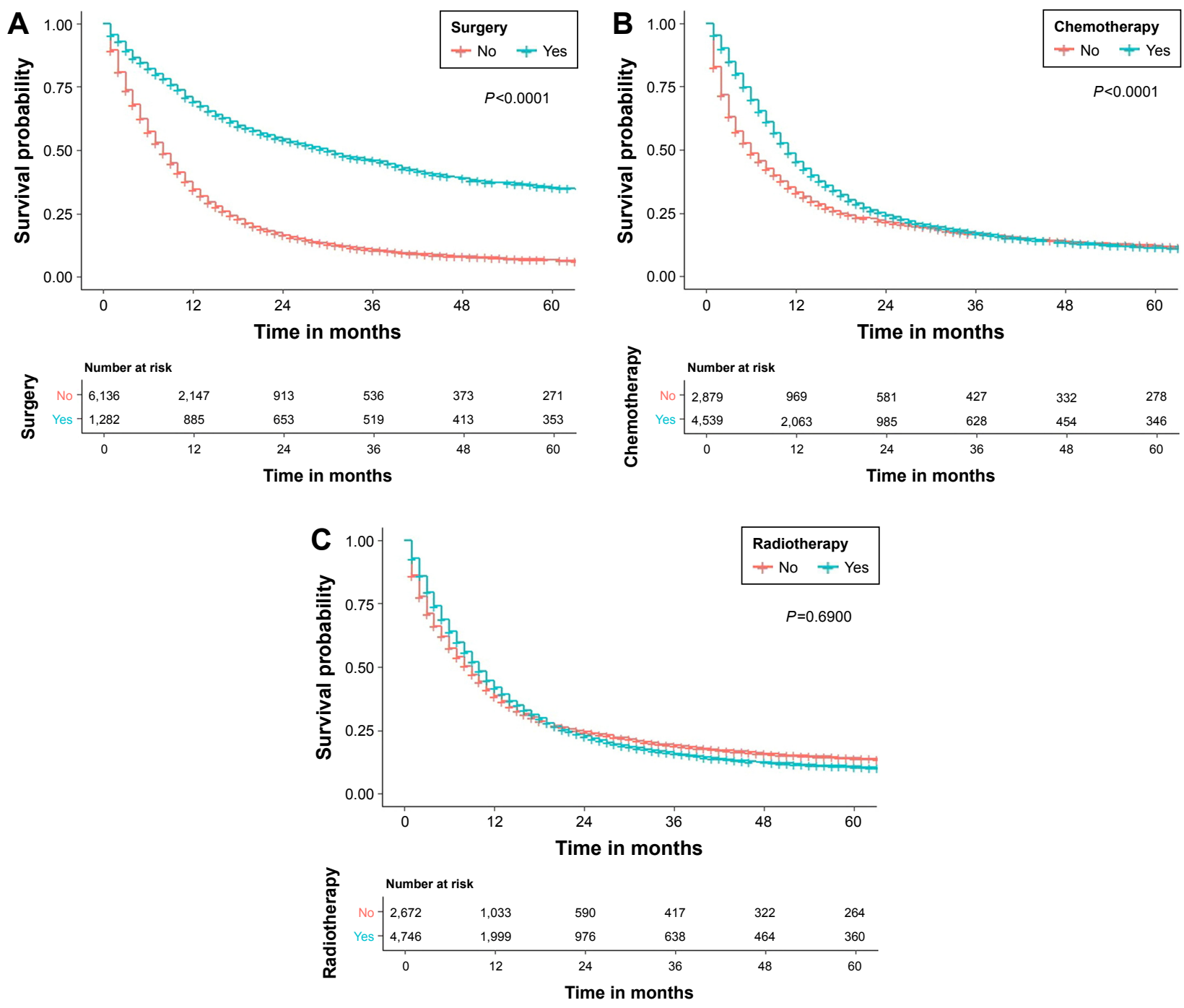

Figure 5 Overall Kaplan-Meier survival curve for patients according to (A) surgery, (B) chemotherapy, and (C) radiotherapy

than past experience. There are no reliable guidelines for treatment of MBTs; thus, designing a prognostic model is one approach to predict the outcome and develop better therapeutic strategies. With univariate and multivariate analyses of 7,418 cases, we identified a group of risk factors, including advanced age, male gender, high pathologic grade, specific histologic types, large tumor size, involvement of lymph nodes, distant extension, and untreated by surgery, radiotherapy, or chemotherapy, then developed a nomogram to predict 1-, 3-, and 5-year OS rates of patients with MBTs visually and intuitively based on these significant factors. In this way, treatment guidelines and prediction of outcomes would be more efficient and accurate for physicians and patients.

It can be seen from the nomogram that one of the most important risk factors impacting OS is age. The prognosis of young patients is far better than older patients. In the elderly, changing the chest wall structure and reduction of the diaphragm curvature reduce the efficiency of respiratory muscles. ${ }^{16}$ In addition, increasing the pulmonary artery and pulmonary wedge pressures and reducing the pulmonary capillary volume compromise gas exchange. ${ }^{17}$ Thus, a decline in pulmonary function with aging would increase the risk of respiratory failure caused by airway obstruction of MBTs in aging patients. Otherwise, many nonpulmonary conditions associated with aging, such as malnutrition, renal failure, and heart disease, would reduce treatment tolerance and worsen the prognosis for elderly patients..$^{18,19}$

Another significant factor was surgery. For those lowgrade MBTs, such as SCC in the early stages, carcinoid tumors, and adenoid cystic cancer, airway resection and reconstruction is considered as a curative approach. ${ }^{20}$ The surgical procedures include sleeve resection, lobectomy, and pneumonectomy, while sleeve resection is widely accepted 
Table I Patient characteristics and I-, 3-, and 5-year OS rates

\begin{tabular}{|c|c|c|c|c|c|}
\hline Variable & $\begin{array}{l}\text { Number } \\
\text { of patients }\end{array}$ & Percent & I-year OS & 3-year OS & 5-year OS \\
\hline Total cases & 7,418 & 100 & $40.7 \% \pm 0.6 \%$ & $17.0 \% \pm 0.4 \%$ & $11.9 \% \pm 0.4 \%$ \\
\hline \multicolumn{6}{|l|}{ Age (years) } \\
\hline $0-39$ & 87 & 1.2 & $63.1 \% \pm 5.3 \%$ & $43.8 \% \pm 5.6 \%$ & $32.0 \% \pm 5.6 \%$ \\
\hline $40-49$ & 486 & 6.6 & $48.5 \% \pm 2.3 \%$ & $23.0 \% \pm 2.0 \%$ & $16.9 \% \pm 1.8 \%$ \\
\hline $50-59$ & I,589 & 21.4 & $45.6 \% \pm 1.3 \%$ & $21.2 \% \pm 1.1 \%$ & $15.5 \% \pm 1.0 \%$ \\
\hline $60-69$ & 2,578 & 34.8 & $42.8 \% \pm 1.0 \%$ & $18.4 \% \pm 0.8 \%$ & $13.0 \% \pm 0.7 \%$ \\
\hline $70-79$ & 2,059 & 27.8 & $35.3 \% \pm 1.1 \%$ & $12.2 \% \pm 0.8 \%$ & $7.9 \% \pm 0.6 \%$ \\
\hline $80+$ & 619 & 8.3 & $27.6 \% \pm 1.8 \%$ & $8.1 \% \pm 1.2 \%$ & $4.2 \% \pm 0.9 \%$ \\
\hline \multicolumn{6}{|l|}{ Gender } \\
\hline Male & 4,305 & 58.0 & $39.8 \% \pm 0.8 \%$ & $17.0 \% \pm 0.6 \%$ & $1 \mathrm{I} .4 \% \pm 0.5 \%$ \\
\hline Female & 3,113 & 42.0 & $41.7 \% \pm 0.9 \%$ & $17.2 \% \pm 0.7 \%$ & $12.6 \% \pm 0.6 \%$ \\
\hline \multicolumn{6}{|l|}{ Pathologic grade } \\
\hline Grade I & 292 & 3.9 & $53.1 \% \pm 3.0 \%$ & $34.3 \% \pm 2.9 \%$ & $27.3 \% \pm 2.8 \%$ \\
\hline Grade II & $\mathrm{I}, 832$ & 24.7 & $46.9 \% \pm 1.2 \%$ & $22.6 \% \pm 1.0 \%$ & $15.8 \% \pm 0.9 \%$ \\
\hline Grade III & 3,478 & 46.9 & $38.0 \% \pm 0.8 \%$ & $15.0 \% \pm 0.6 \%$ & $10.4 \% \pm 0.6 \%$ \\
\hline Grade IV & 1,816 & 24.5 & $37.5 \% \pm 1.1 \%$ & $12.7 \% \pm 0.8 \%$ & $8.6 \% \pm 0.7 \%$ \\
\hline \multicolumn{6}{|l|}{ Histologic type } \\
\hline SQCC & 3,168 & 42.7 & $44.3 \% \pm 0.9 \%$ & $20.7 \% \pm 0.7 \%$ & $14.5 \% \pm 0.7 \%$ \\
\hline$A C$ & $\mathrm{I}, 676$ & 22.6 & $37.2 \% \pm 1.2 \%$ & $14.9 \% \pm 0.9 \%$ & $9.4 \% \pm 0.8 \%$ \\
\hline LCC & 386 & 5.2 & $32.1 \% \pm 2.4 \%$ & $12.1 \% \pm 1.7 \%$ & $8.9 \% \pm 1.5 \%$ \\
\hline SMCC & I,796 & 24.2 & $39.1 \% \pm 1.2 \%$ & $11.8 \% \pm 0.8 \%$ & $8.1 \% \pm 0.7 \%$ \\
\hline Others & 392 & 5.3 & $41.7 \% \pm 2.5 \%$ & $26.5 \% \pm 2.3 \%$ & $21.8 \% \pm 2.2 \%$ \\
\hline \multicolumn{6}{|l|}{ Radiotherapy } \\
\hline No & 2,672 & 36.0 & $38.5 \% \pm 1.0 \%$ & $19.0 \% \pm 0.8 \%$ & $14.1 \% \pm 0.7 \%$ \\
\hline Yes & 4,756 & 64.0 & $41.9 \% \pm 0.7 \%$ & $15.9 \% \pm 0.6 \%$ & $10.7 \% \pm 0.5 \%$ \\
\hline \multicolumn{6}{|l|}{ RT without surgery } \\
\hline No RT & 4,202 & 56.6 & $24.6 \% \pm 1.0 \%$ & $5.1 \% \pm 0.5 \%$ & $3.1 \% \pm 0.4 \%$ \\
\hline Underwent RT & 1,934 & 26.1 & $39.1 \% \pm 0.8 \%$ & $13.2 \% \pm 0.6 \%$ & $8.3 \% \pm 0.5 \%$ \\
\hline \multicolumn{6}{|l|}{ RT with surgery } \\
\hline No RT & 738 & 9.9 & $74.1 \% \pm 1.6 \%$ & $53.3 \% \pm 1.9 \%$ & $40.5 \% \pm 1.9 \%$ \\
\hline Underwent RT & 544 & 7.3 & $62.5 \% \pm 2.1 \%$ & $36.2 \% \pm 2.1 \%$ & $28.1 \% \pm 2.0 \%$ \\
\hline \multicolumn{6}{|l|}{ Chemotherapy } \\
\hline No & 2,879 & 38.8 & $33.2 \% \pm 0.9 \%$ & $16.9 \% \pm 0.7 \%$ & $12.1 \% \pm 0.6 \%$ \\
\hline Yes & 4,539 & 61.2 & $45.4 \% \pm 0.8 \%$ & $17.1 \% \pm 0.6 \%$ & $11.7 \% \pm 0.5 \%$ \\
\hline \multicolumn{6}{|l|}{ Surgery } \\
\hline No & 6,136 & 82.7 & $34.6 \% \pm 0.6 \%$ & $10.7 \% \pm 0.4 \%$ & $6.7 \% \pm 0.4 \%$ \\
\hline Yes & $\mathrm{I}, 403$ & 17.3 & $69.2 \% \pm 1.3 \%$ & $46.0 \% \pm 1.4 \%$ & $35.2 \% \pm 1.4 \%$ \\
\hline \multicolumn{6}{|l|}{ Size $(\mathrm{cm})$} \\
\hline$<2$ & 349 & 4.7 & $55.5 \% \pm 2.7 \%$ & $32.7 \% \pm 2.6 \%$ & $24.0 \% \pm 2.5 \%$ \\
\hline $2-3.9$ & $\mathrm{I}, 874$ & 25.3 & $48.8 \% \pm 1.2 \%$ & $24.2 \% \pm 1.0 \%$ & $17.5 \% \pm 0.9 \%$ \\
\hline $4-5.9$ & 2,695 & 36.3 & $40.5 \% \pm 1.0 \%$ & $15.5 \% \pm 0.7 \%$ & $10.4 \% \pm 0.6 \%$ \\
\hline $6-7.9$ & $|, 54|$ & 20.7 & $34.9 \% \pm 1.2 \%$ & $12.1 \% \pm 0.9 \%$ & $8.3 \% \pm 0.8 \%$ \\
\hline $8-9.9$ & 633 & 8.5 & $29.0 \% \pm 1.9 \%$ & $10.6 \% \pm 1.3 \%$ & $7.4 \% \pm 1.1 \%$ \\
\hline$\geq 10$ & 326 & 4.4 & $27.9 \% \pm 2.5 \%$ & $7.3 \% \pm 1.6 \%$ & $4.1 \% \pm 1.2 \%$ \\
\hline \multicolumn{6}{|l|}{ Involvement of LN } \\
\hline No & $\mathrm{I}, 90 \mathrm{I}$ & 25.6 & $51.4 \% \pm 1.2 \%$ & $26.8 \% \pm 1.1 \%$ & $20.3 \% \pm 1.0 \%$ \\
\hline Regional LN & 4,820 & 65.0 & $37.8 \% \pm 0.7 \%$ & $14.4 \% \pm 0.5 \%$ & $9.5 \% \pm 0.5 \%$ \\
\hline Distant LN & 697 & 9.4 & $31.2 \% \pm 1.8 \%$ & $8.1 \% \pm 1.2 \%$ & $4.7 \% \pm 1.0 \%$ \\
\hline \multicolumn{6}{|l|}{ Extension of tumor } \\
\hline No & 3,352 & 45.2 & $51.3 \% \pm 0.9 \%$ & $24.9 \% \pm 0.8 \%$ & $18.4 \% \pm 0.7 \%$ \\
\hline Distant extension & 4,066 & 54.8 & $32.0 \% \pm 0.7 \%$ & $10.7 \% \pm 0.5 \%$ & $6.7 \% \pm 0.4 \%$ \\
\hline \multicolumn{6}{|l|}{ Race } \\
\hline White & 6,113 & 82.4 & $40.7 \% \pm 0.6 \%$ & $17.1 \% \pm 0.5 \%$ & $12.2 \% \pm 0.5 \%$ \\
\hline Black & 924 & 12.5 & $39.5 \% \pm 1.6 \%$ & $16.9 \% \pm 1.3 \%$ & $10.9 \% \pm 1.1 \%$ \\
\hline Asian & 375 & 5.1 & $42.7 \% \pm 2.6 \%$ & $17.4 \% \pm 2.1 \%$ & $10.4 \% \pm 1.7 \%$ \\
\hline
\end{tabular}

Abbreviations: OS, overall survival; SQCC, squamous cell carcinoma; AC, adenocarcinoma; LCC, large cell carcinoma; SMCC, small cell carcinoma; RT, radiotherapy; LN, lymph node. 
Table 2 Univariable analysis and Cox proportional hazards regression analysis

\begin{tabular}{|c|c|c|c|c|c|c|}
\hline \multirow[t]{2}{*}{ Variable } & \multicolumn{3}{|c|}{ Univariable analysis } & \multicolumn{3}{|c|}{ Multivariable analysis } \\
\hline & Hazard ratio & $95 \% \mathrm{Cl}$ & $P$-value & Hazard ratio & $95 \% \mathrm{Cl}$ & $P$-value \\
\hline \multicolumn{7}{|l|}{ Age (years) } \\
\hline $0-39$ & Ref & & & Ref & & \\
\hline $40-49$ & 1.859 & $1.399-2.469$ & $<0.001$ & 1.495 & $1.124-1.989$ & 0.006 \\
\hline $50-59$ & 1.960 & $1.492-2.573$ & $<0.001$ & 1.565 & I.190-2.059 & 0.001 \\
\hline $60-69$ & 2.171 & $1.657-2.845$ & $<0.001$ & 1.650 & $1.257-2.167$ & $<0.001$ \\
\hline $70-79$ & 2.714 & $2.069-3.559$ & $<0.001$ & 1.896 & I.442-2.492 & $<0.001$ \\
\hline $80+$ & 3.348 & $2.531-4.429$ & $<0.001$ & 2.057 & $1.550-2.728$ & $<0.001$ \\
\hline \multicolumn{7}{|l|}{ Gender } \\
\hline Male & Ref & & & Ref & & \\
\hline Female & 0.953 & $0.907-1.00 \mathrm{I}$ & 0.054 & 0.893 & $0.849-0.939$ & $<0.001$ \\
\hline \multicolumn{7}{|l|}{ Pathologic grade } \\
\hline Grade I & Ref & & & Ref & & \\
\hline Grade II & 1.350 & $1.169-1.559$ & $<0.001$ & 1.233 & $1.065-1.427$ & 0.005 \\
\hline Grade III & 1.675 & I.457-1.927 & $<0.001$ & 1.394 & $1.210-1.606$ & $<0.001$ \\
\hline Grade IV & 1.736 & $1.504-2.004$ & $<0.001$ & 1.389 & $1.718-1.637$ & $<0.001$ \\
\hline \multicolumn{7}{|l|}{ Histologic type } \\
\hline SQCC & Ref & & & Ref & & \\
\hline $\mathrm{AC}$ & 1.187 & $1.114-1.265$ & $<0.001$ & 1.083 & $1.014-1.156$ & 0.017 \\
\hline LCC & $|.34|$ & $1.202-1.497$ & $<0.001$ & $\mathrm{I} .034$ & $0.915-1.167$ & 0.594 \\
\hline SMCC & 1.188 & $1.117-1.263$ & $<0.001$ & 0.955 & $0.863-1.057$ & 0.375 \\
\hline Others & 0.866 & $0.770-0.975$ & 0.017 & 1.000 & $0.884-1.13 \mid$ & 0.997 \\
\hline \multicolumn{7}{|l|}{ Chemotherapy } \\
\hline No & Ref & & & Ref & & \\
\hline Yes & 0.812 & $0.773-0.854$ & $<0.001$ & 0.561 & $0.530-0.593$ & $<0.001$ \\
\hline \multicolumn{7}{|l|}{ Radiotherapy } \\
\hline No & Ref & & & & & \\
\hline Yes & 1.010 & $0.960-1.063$ & 0.694 & & & \\
\hline \multicolumn{7}{|l|}{ Surgery } \\
\hline No & Ref & & & Ref & & \\
\hline Yes & 0.387 & $0.360-0.415$ & $<0.001$ & 0.352 & $0.324-0.382$ & $<0.001$ \\
\hline \multicolumn{7}{|l|}{ Size $(\mathrm{cm})$} \\
\hline$<2$ & Ref & & & Ref & & \\
\hline $2-3.9$ & 1.253 & $1.100-1.427$ & 0.001 & I.107 & $0.97|-| .62 \mid$ & 0.127 \\
\hline $4-5.9$ & 1.558 & $1.373-1.769$ & $<0.001$ & 1.259 & I.107-1.432 & $<0.001$ \\
\hline $6-7.9$ & 1.764 & $1.547-2.012$ & $<0.001$ & 1.357 & I.187-I.552 & $<0.001$ \\
\hline $8-9.9$ & 1.992 & $1.722-2.305$ & $<0.001$ & 1.422 & $|.225-| .65 \mid$ & $<0.001$ \\
\hline$\geq 10$ & 2.195 & $1.860-2.590$ & $<0.001$ & 1.509 & $1.274-1.788$ & $<0.001$ \\
\hline \multicolumn{7}{|l|}{ Involvement of LN } \\
\hline No & Ref & & & Ref & & \\
\hline Regional LN & 1.410 & $1.330-1.494$ & $<0.001$ & 1.279 & $1.204-1.658$ & $<0.001$ \\
\hline Distant LN & 1.739 & $1.583-1.911$ & $<0.001$ & 1.456 & $1.32 \mid-1.604$ & $<0.001$ \\
\hline \multicolumn{7}{|l|}{ Extension of tumor } \\
\hline No & Ref & & & Ref & & \\
\hline Distant extension & 1.582 & $1.505-1.662$ & $<0.001$ & 1.333 & $1.265-1.406$ & $<0.001$ \\
\hline
\end{tabular}

Abbreviations: SQCC, squamous cell carcinoma; AC, adenocarcinoma; LCC, large cell carcinoma; SMCC, small cell carcinoma; LN, lymph node.

for the management of MBTs because the lung parenchyma and pulmonary preservation are preserved., ${ }^{1,5,21}$ If resectable, a number of low-grade MBTs have no tendency for recurrence. ${ }^{20}$ Like tracheal tumors, negative surgical margins and lymph node status have a significant association with survival outcomes of MBTs; $;, 21$ however, with the development of endoscopy, those patients with nonresectable MBTs or at high surgical risk will benefit from a bronchoscopic approach. Bronchoscopic resection has shown good outcomes in a number of MBTs. ${ }^{22-24}$ Photodynamic therapy, cryotherapy, and airway stenting are alternatives under bronchoscopy in the case of central airway obstruction. ${ }^{25-27}$

On the basis of univariate analysis and a competing risk model, radiotherapy was not a risk factor for OS. 


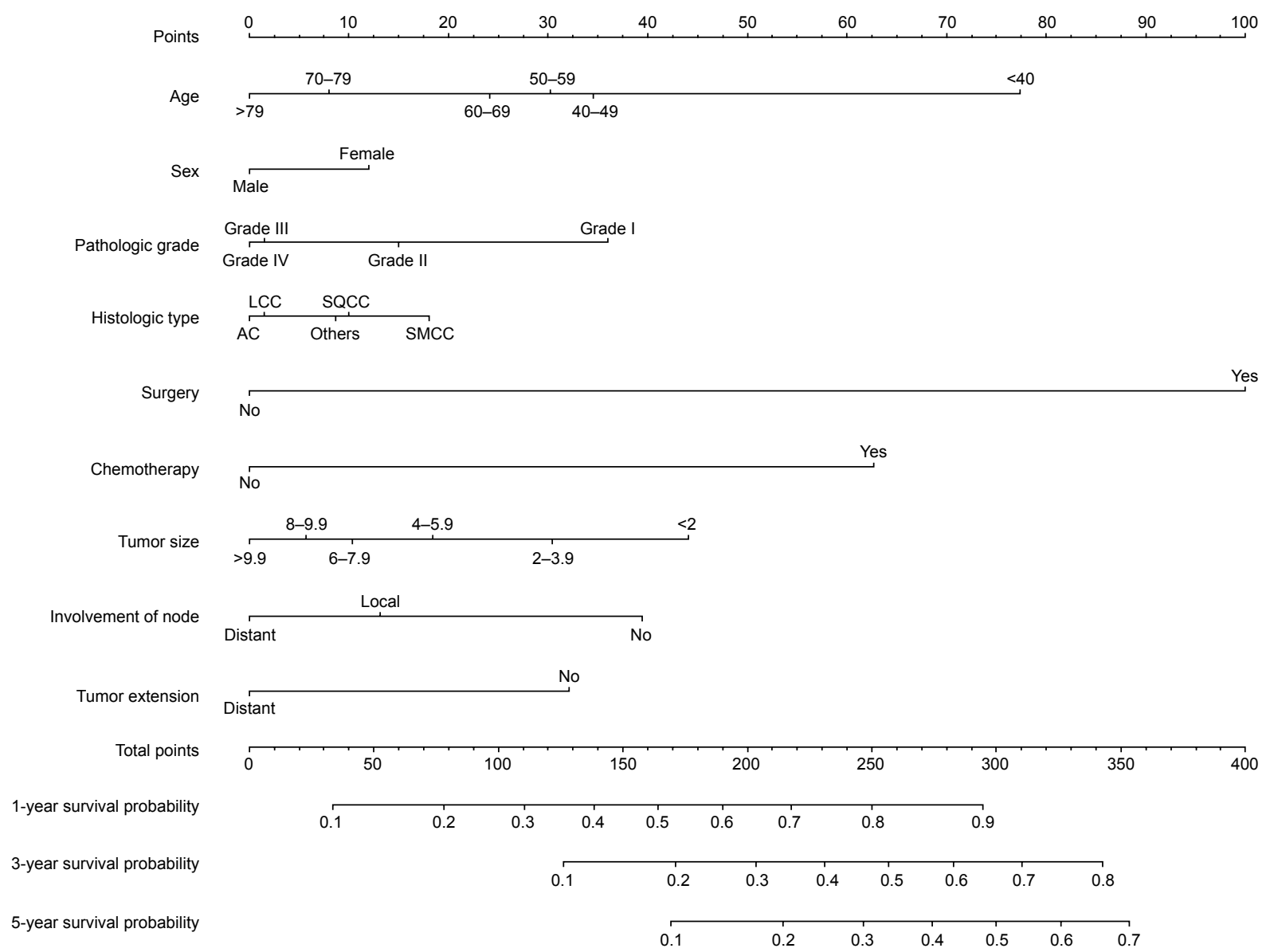

Figure 6 A nomogram for prediction of I-, 3-, and 5-year OS rates of patients with MBTs.

Abbreviations: OS, overall survival; MBTs, malignant main stem bronchial tumors; SQCC, squamous cell carcinoma; AC, adenocarcinoma; LCC, large cell carcinoma; SMCC, small cell carcinoma; .

Current studies about the effect of radiotherapy for MBTs support the opposite view. Among traditional laser therapies, the neodymium yttrium-aluminum-garnet laser is one of the most used techniques for tumor debulking and urgent deobstruction, and shows an improvement in OS and quality of life. ${ }^{28,29}$ In contrast, it is proposed that radiotherapy improves the risk of pulmonary function injury and pneumonia, and both local recurrence and toxicity occur late after radiotherapy in patients with central tumors. ${ }^{30-32}$ As the result of our study, it is suggested that radiotherapy is more appropriate for nonsurgical patients, but not helpful to surgical patients. Nevertheless, MBT patients would likely benefit in some ways with new techniques of radiotherapy. Stereotactic body radiotherapy has shown excellent effects in patients with inoperative bronchial carcinoid and neuroendocrine tumors. ${ }^{33}$ The application of external beam radiotherapy is an alternative to reduce airway stenosis caused by MBTs. ${ }^{34}$ With the advent of bronchoscopy, brachytherapy has shown a promising effect as a palliative and curative treatment for endobronchial tumors. ${ }^{35,36}$ Chemotherapy also plays a role in some types of MBTs. Most of the patients who receive chemotherapy have small-cell carcinomas, and benefit most from chemotherapy ${ }^{37}$ Chemotherapy has become an approach for malignant obstruction of the main bronchus with the development of intratumoral chemotherapy, which leads to a favorable reduction in massive non-small-cell lung cancer. Chemotherapy showed a positive effect based on multivariate analysis and the nomogram; however, patients with chemotherapy had a better short-term survival rate, but those who without that treatment had favorable long-term rates using the Kaplan-Meier method. It should be noted that patients treated with radiotherapy and chemotherapy were usually linked to an advanced stage and a worse physical condition. Thus, more research is needed to determine the effect of radiotherapy and chemotherapy in the treatment of MBTs.

Among characteristics of MBTs, histologic types have the most important influence on outcome because only earlystage or slow-growing MBTs are considered resectable. ${ }^{20}$ Tumor size also plays a significant role in predicting prognosis because a large tumor would cause worse airway obstruction and an excessive length of the involved airway is inoperable. ${ }^{38}$ 

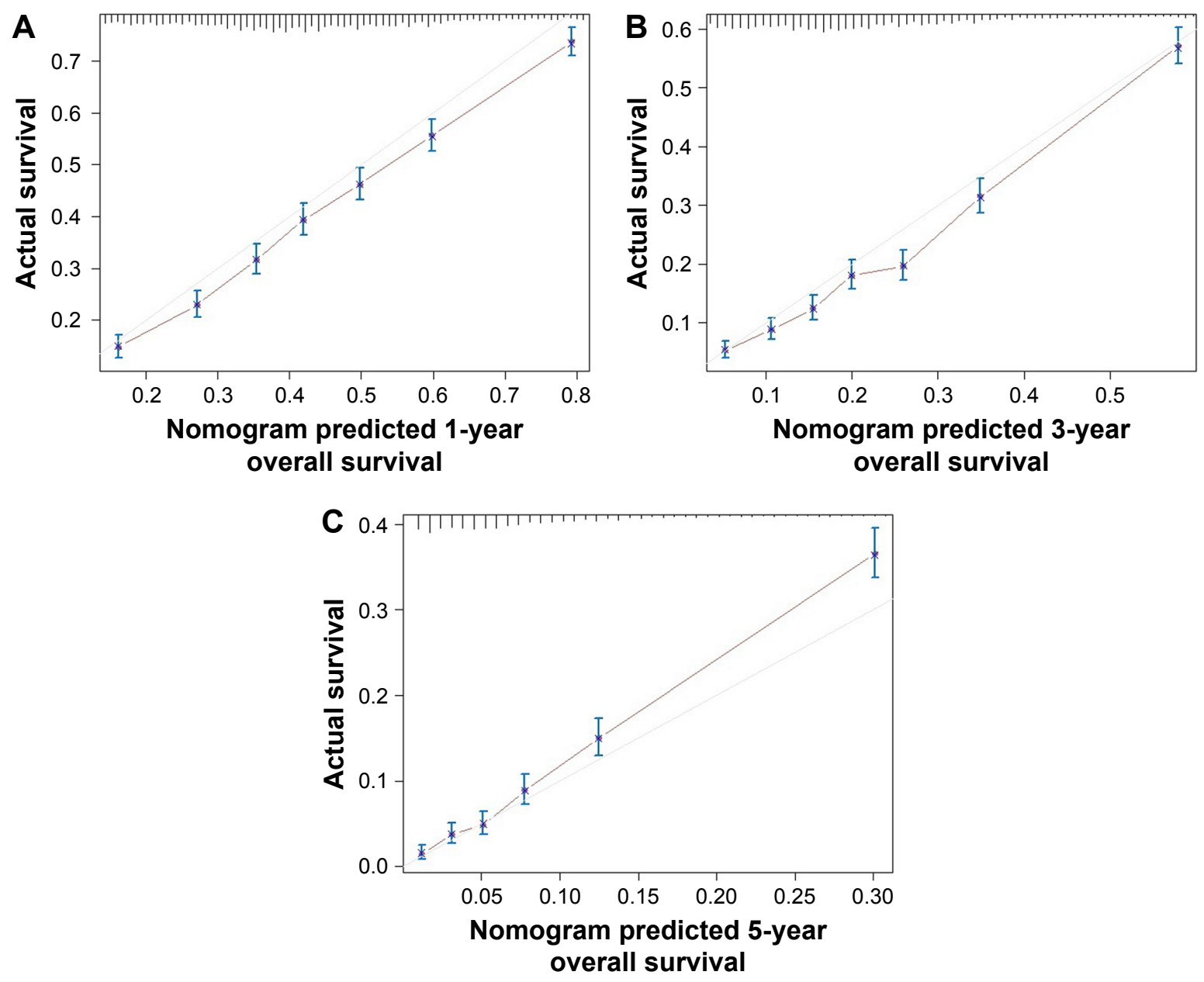

Figure 7 Calibration curve of the nomogram predicting (A) I-year, (B) 3-year, and (C) 5-year OS rates of patients with MBTs. Abbreviations: OS, overall survival; MBTs, malignant main stem bronchial tumors.

This study had several limitations. First, pulmonary function of MBT patients, which is believed to be an important factor for prognosis, was not evaluated. In addition, we could not obtain complete medical histories, such as smoking history or occurrence of complications. Furthermore, progression-free survival is not recorded in the SEER database, and therefore it was not taken into statistics.

\section{Conclusion}

Age, gender, pathologic grade, histologic type, tumor size, involvement of lymph nodes, tumor extension, chemotherapy, and surgery were independent risk factors for OS of patients with MBTs. A nomogram was developed to predict 1-, 3-, and 5-year OS for these patients.

\section{Acknowledgments}

This work was supported by the National Natural Science Foundation of China (Grant numbers 81472225, 81401875 [www.nsfc.gov.cn/]), and the Research Program of Shanghai Health and Family Planning Commission (201640102 [http:// www.wsjsw.gov.cn]). We thank the International Science Editing Co. for editing the language.

\section{Author contribution}

Ke Ma, Fenghao Sun, Xiaodong Yang, Cheng Zhan, and Qun Wang conceived the study design. Data acquisition was carried out by Ke Ma, Fenghao Sun, Xiaodong Yang, Shuai Wang, and Yulin Jin. Ke Ma, Fenghao Sun, Xiaodong Yang, and Cheng Zhan did the data analysis. Data interpretation was done by Shuai Wang, Lin Wang, Yu Shi, Wei Jiang, Cheng Zhan, Lin Wang, and Qun Wang. Ke Ma, Fenghao Sun, Xiaodong Yang, Yulin Jin, Yu Shi, and Wei Jiang drafted the manuscript. Revision of the manuscript was done by Yu Shi, Wei Jiang, and Qun Wang. All authors contributed toward data analysis, drafting and critically revising the paper and agree to be accountable for all aspects of the work. 


\section{Disclosure}

The authors report no conflicts of interest in this work.

\section{References}

1. Stevic R, Milenkovic B. Tracheobronchial tumors. J Thorac Dis. 2016; 8(11):3401-3413.

2. Stevic R, Milenkovic B, Stojsic J, Pesut D, Ercegovac M, Jovanovic D. Clinical and radiological manifestations of primary tracheobronchial tumours: a single centre experience. Ann Acad Med Singapore. 2012; 41(5):205-211.

3. Takeda S, Hashimoto T, Kusu T, et al. Management and surgical resection for tracheobronchial tumors institutional experience with 12 patients. Interact Cardiovasc Thorac Surg. 2007;6(4):484-489.

4. Saoud M, Patil M, Dhillon SS, et al. Rare airway tumors: an update on current diagnostic and management strategies. J Thorac Dis. 2016; 8(8):1922-1934.

5. Jiang X, Dong X, Zhao X, Peng C. Bronchial sleeve resection distal to the main bronchus with complete pulmonary preservation for benign or low-grade malignant tumors. Ann Thorac Surg. 2007;84(4):e19-e21.

6. Li Z, Zarogoulidis P, Kougioumtzi I, et al. Surgical approaches of endobronchial neoplasms. J Thorac Dis. 2013;5(Suppl 4):S378-S382.

7. Liang W, Zhang L, Jiang G, et al. Development and validation of a nomogram for predicting survival in patients with resected non-smallcell lung cancer. J Clin Oncol. 2015;33(8):861-869.

8. Zhou Z, Zhang H, Xu Z, Li W, Dang C, Song Y. Nomogram predicted survival of patients with adenocarcinoma of esophagogastric junction. World J Surg Oncol. 2015;13:197.

9. Valentini V, van Stiphout RG, Lammering G, et al. Nomograms for predicting local recurrence, distant metastases, and overall survival for patients with locally advanced rectal cancer on the basis of European randomized clinical trials. J Clin Oncol. 2011;29(23):3163-3172.

10. Sun F, Ma K, Yang X, et al. A nomogram to predict prognosis after surgery in early stage non-small cell lung cancer in elderly patients Int J Surg. 2017;42:11-16.

11. Iasonos A, Schrag D, Raj GV, et al. How to build and interpret a nomogram for cancer prognosis. J Clin Oncol. 2008;26(8):1364-1370.

12. National Cancer Institute: Surveillance, Epidemiology, and End Results. Available from: http://www.seer.cancer.gov

13. Southern DA, Faris PD, Brant R, et al. Kaplan-Meier methods yielded misleading results in competing risk scenarios. $J$ Clin Epidemiol. 2006;59(10):1110-1114.

14. Harrell FE. Quantifying Predictive Ability. Regression Modeling Strategies: With Applications to Linear Models, Logistic Regression, and Survival Analysis (Springer Series in Statistics). New York: Springer; 2015.

15. Available from: http://www.stat.unipg.it/luca/R/

16. Sprung J, Gajic O, Warner DO. Review article: age related alterations in respiratory function - anesthetic considerations. Can J Anaesth. 2006;53(12):1244-1257.

17. Taylor BJ, Johnson BD. The pulmonary circulation and exercise responses in the elderly. Semin Respir Crit Care Med. 2010;31(5): $528-538$.

18. Hedlund J, Hansson LO, Ortqvist A. Short- and long-term prognosis for middle-aged and elderly patients hospitalized with community-acquired pneumonia: impact of nutritional and inflammatory factors. Scand $J$ Infect Dis. 1995;27(1):32-37.

19. El Solh AA, Ramadan FH. Overview of respiratory failure in older adults. J Intensive Care Med. 2006;21(6):345-351.
20. Shadmehr MB, Farzanegan R, Graili P, et al. Primary major airway tumors; management and results. Eur J Cardiothorac Surg. 2011;39(5): 749-754.

21. Cerfolio RJ, Deschamps C, Allen MS, Trastek VF, Pairolero PC. Mainstem bronchial sleeve resection with pulmonary preservation. Ann Thorac Surg. 1996;61(5):1458-1462; discussion 1462-1463.

22. Jennings $S$, Tharion J, Jones $P$, et al. Bronchial haemangioma: exceptionally rare cause of haemoptysis. Heart Lung Circ. 2013;22(12):1030-1032.

23. Luckraz H, Amer K, Thomas L, et al. Long-term outcome of bronchoscopically resected endobronchial typical carcinoid tumors. J Thorac Cardiovasc Surg. 2006;132(1):113-115.

24. Sim JK, Choi JH, Oh JY, et al. Two cases of diagnosis and removal of endobronchial hamartoma by cryotherapy via flexible bronchoscopy. Tuberc Respir Dis. 2014;76(3):141-145.

25. Minnich DJ, Bryant AS, Dooley A, Cerfolio RJ. Photodynamic laser therapy for lesions in the airway. Ann Thorac Surg. 2010;89(6): 1744-1748; discussion 1748-1749.

26. Finley DJ, Dycoco J, Sarkar S, et al. Airway spray cryotherapy: initial outcomes from a multiinstitutional registry. Ann Thorac Surg. 2012;94(1):199-203; discussion 203-204.

27. Saji H, Furukawa K, Tsutsui H, et al. Outcomes of airway stenting for advanced lung cancer with central airway obstruction. Interact Cardiovasc Thorac Surg. 2010;11(4):425-428.

28. Zaric B, Kovacevic T, Stojsic V, et al. Neodymium yttrium-aluminiumgarnet laser resection significantly improves quality of life in patients with malignant central airway obstruction due to lung cancer. Eur $J$ Cancer Care (Engl). 2015;24(4):560-566.

29. Ernst A, Feller-Kopman D, Becker HD, et al. Central airway obstruction. Am J Respir Crit Care Med. 2004;169(12):1278-1297.

30. Hetzel MR, Millard FJ, Ayesh R, et al. Laser treatment for carcinoma of the bronchus. Br Med J (Clin Res Ed). 1983;286(6358):12-16.

31. Chella A, Ambrogi MC, Ribechini A, et al. Combined Nd-YAG laser/ HDR brachytherapy versus Nd-YAG laser only in malignant central airway involvement: a prospective randomized study. Lung Cancer. 2000;27(3):169-175.

32. Timmerman R, McGarry R, Yiannoutsos C, et al. Excessive toxicity when treating central tumors in a phase II study of stereotactic body radiation therapy for medically inoperable early-stage lung cancer. J Clin Oncol. 2006;24(30):4833-4839.

33. Colaco RJ, Decker RH. Stereotactic radiotherapy in the treatment of primary bronchial carcinoid tumor. Clin Lung Cancer. 2015;16(2): e11-e14.

34. Tanaka H, Hayashi S, Ohtakara K, et al. Palliative radiotherapy for patients with tracheobronchial and esophageal compression due to intrathoracic malignant tumors. Asia Pac J Clin Oncol. 2012;8(4):e82-e88.

35. Hosni A, Bezjak A, Rink A, et al. High dose rate brachytherapy as a treatment option in endobronchial tumors. Lung Cancer Int. 2016;2016: 3086148.

36. Dagnault A, Ebacher A, Vigneault E, et al. Retrospective study of 81 patients treated with brachytherapy for endobronchial primary tumor or metastasis. Brachytherapy. 2010;9(3):243-247.

37. Verma V, Simone CB, Allen PK, Lin SH. Outcomes of stereotactic body radiotherapy for T1-T2N0 small cell carcinoma according to addition of chemotherapy and prophylactic cranial irradiation: a multicenter analysis. Clin Lung Cancer. 2017;18(6):675.e1-681.e1.

38. Gaissert HA, Grillo HC, Shadmehr MB, et al. Long-term survival after resection of primary adenoid cystic and squamous cell carcinoma of the trachea and carina. Ann Thorac Surg. 2004;78(6):1889-1896; discussion 1896-1897. 


\section{Supplementary material}

Table SI CIF of MBT-specific death based on competing risk model

\begin{tabular}{|c|c|c|c|c|}
\hline Variable & I-year CIF & 3-year CIF & 5-year CIF & $\begin{array}{l}\text { Gray's test } \\
\text { P-value }\end{array}$ \\
\hline Age (years) & & & & 0.006 \\
\hline $0-39$ & $34.5 \% \pm 5.1 \%$ & $50.8 \% \pm 5.4 \%$ & $58.6 \% \pm 5.3 \%$ & \\
\hline $40-49$ & $45.7 \% \pm 2.3 \%$ & $66.9 \% \pm 2.1 \%$ & $70.8 \% \pm 2.1 \%$ & \\
\hline $50-59$ & $45.1 \% \pm 1.2 \%$ & $62.2 \% \pm 1.2 \%$ & $65.8 \% \pm 1.2 \%$ & \\
\hline $60-69$ & $45.5 \% \pm 1.0 \%$ & $61.6 \% \pm 0.9 \%$ & $64.4 \% \pm 0.9 \%$ & \\
\hline $70-79$ & $45.3 \% \pm 1.1 \%$ & $59.3 \% \pm 1.1 \%$ & $61.4 \% \pm 1.1 \%$ & \\
\hline $80+$ & $47.2 \% \pm 2.0 \%$ & $56.9 \% \pm 1.9 \%$ & $58.2 \% \pm 1.9 \%$ & \\
\hline Gender & & & & 0.048 \\
\hline Male & $46.2 \% \pm 0.8 \%$ & $61.6 \% \pm 0.7 \%$ & $64.6 \% \pm 0.7 \%$ & \\
\hline Female & $44.3 \% \pm 0.9 \%$ & $60.1 \% \pm 0.9 \%$ & $62.3 \% \pm 0.8 \%$ & \\
\hline Pathologic grade & & & & $<0.001$ \\
\hline Grade I & $34.2 \% \pm 2.8 \%$ & $46.6 \% \pm 2.9 \%$ & $49.7 \% \pm 2.9 \%$ & \\
\hline Grade II & $38.9 \% \pm 1.1 \%$ & $53.5 \% \pm 1.2 \%$ & $56.6 \% \pm 1.1 \%$ & \\
\hline Grade III & $47.4 \% \pm 0.8 \%$ & $62.4 \% \pm 0.8 \%$ & $65.0 \% \pm 0.8 \%$ & \\
\hline Grade IV & $50.0 \% \pm 1.2 \%$ & $68.0 \% \pm 1.1 \%$ & $70.8 \% \pm 1.0 \%$ & \\
\hline Histologic type & & & & $<0.001$ \\
\hline SCC & $41.8 \% \pm 0.9 \%$ & $56.8 \% \pm 0.9 \%$ & $60.0 \% \pm 0.9 \%$ & \\
\hline$A C$ & $46.9 \% \pm 1.2 \%$ & $60.3 \% \pm 1.2 \%$ & $63.3 \% \pm 1.2 \%$ & \\
\hline LCC & $52.3 \% \pm 2.5 \%$ & $67.1 \% \pm 2.4 \%$ & $68.9 \% \pm 2.3 \%$ & \\
\hline SMCC & $49.4 \% \pm 1.2 \%$ & $69.3 \% \pm 1.1 \%$ & $71.8 \% \pm 1.0 \%$ & \\
\hline Others & $42.3 \% \pm 2.5 \%$ & $52.3 \% \pm 2.5 \%$ & $54.3 \% \pm 2.5 \%$ & \\
\hline Radiotherapy & & & & 0.409 \\
\hline No & $46.7 \% \pm 1.0 \%$ & $59.4 \% \pm 0.9 \%$ & $61.8 \% \pm 0.9 \%$ & \\
\hline Yes & $44.6 \% \pm 0.7 \%$ & $61.8 \% \pm 0.7 \%$ & $64.8 \% \pm 0.7 \%$ & \\
\hline Chemotherapy & & & & 0.030 \\
\hline No & $49.5 \% \pm 0.9 \%$ & $59.5 \% \pm 0.9 \%$ & $62.0 \% \pm 0.9 \%$ & \\
\hline Yes & $42.7 \% \pm 0.7 \%$ & $61.8 \% \pm 0.7 \%$ & $64.8 \% \pm 0.7 \%$ & \\
\hline Surgery & & & & $<0.001$ \\
\hline No & $50.3 \% \pm 0.6 \%$ & $66.2 \% \pm 0.6 \%$ & $68.3 \% \pm 0.6 \%$ & \\
\hline Yes & $21.5 \% \pm 1.1 \%$ & $35.9 \% \pm 1.3 \%$ & $41.7 \% \pm 1.4 \%$ & \\
\hline Size $(\mathrm{cm})$ & & & & $<0.00 \mathrm{I}$ \\
\hline$<2$ & $27.8 \% \pm 2.4 \%$ & $40.7 \% \pm 2.6 \%$ & $44.4 \% \pm 2.6 \%$ & \\
\hline $2-3.9$ & $38.5 \% \pm 1.1 \%$ & $53.4 \% \pm 1.1 \%$ & $57.4 \% \pm 1.1 \%$ & \\
\hline $4-5.9$ & $46.4 \% \pm 0.9 \%$ & $63.0 \% \pm 0.9 \%$ & $65.7 \% \pm 0.9 \%$ & \\
\hline $6-7.9$ & $50.6 \% \pm 1.3 \%$ & $66.8 \% \pm 1.2 \%$ & $68.5 \% \pm 1.2 \%$ & \\
\hline $8-9.9$ & $54.5 \% \pm 2.0 \%$ & $66.8 \% \pm 1.8 \%$ & $68.6 \% \pm 1.8 \%$ & \\
\hline$\geq 10$ & $54.6 \% \pm 2.7 \%$ & $69.6 \% \pm 2.5 \%$ & $71.5 \% \pm 2.4 \%$ & \\
\hline Lymph node & & & & $<0.001$ \\
\hline No & $34.9 \% \pm 1.1 \%$ & $49.8 \% \pm 1.1 \%$ & $53.2 \% \pm 1.1 \%$ & \\
\hline Regional LN & $48.5 \% \pm 0.7 \%$ & $64.5 \% \pm 0.7 \%$ & $67.2 \% \pm 0.7 \%$ & \\
\hline Distant LN & $52.2 \% \pm 1.9 \%$ & $67.0 \% \pm 1.7 \%$ & $68.6 \% \pm 1.7 \%$ & \\
\hline Extension of tumor & & & & $<0.001$ \\
\hline No & $35.6 \% \pm 0.8 \%$ & $51.7 \% \pm 0.9 \%$ & $55.1 \% \pm 0.9 \%$ & \\
\hline Distant extension & $53.4 \% \pm 0.8 \%$ & $68.6 \% \pm 0.7 \%$ & $70.8 \% \pm 0.7 \%$ & \\
\hline Race & & & & 0.506 \\
\hline White & $45.3 \% \pm 0.6 \%$ & $60.9 \% \pm 0.6 \%$ & $63.5 \% \pm 0.6 \%$ & \\
\hline Black & $46.8 \% \pm 1.6 \%$ & $61.1 \% \pm 1.6 \%$ & $64.5 \% \pm 1.5 \%$ & \\
\hline Others & $43.2 \% \pm 2.5 \%$ & $61.3 \% \pm 2.4 \%$ & $65.3 \% \pm 2.4 \%$ & \\
\hline
\end{tabular}

Abbreviations: CIF, cumulative incidence function; MBTs, malignant main stem bronchial tumors; SQCC, squamous cell carcinoma; AC, adenocarcinoma; LCC, large-cell carcinoma; SMCC, small-cell carcinoma; LN, lymph node. 
OncoTargets and Therapy

\section{Publish your work in this journal}

OncoTargets and Therapy is an international, peer-reviewed, open access journal focusing on the pathological basis of all cancers, potential targets for therapy and treatment protocols employed to improve the management of cancer patients. The journal also focuses on the impact of management programs and new therapeutic agents and protocols on The manuscript management system is completely online and includes a very quick and fair peer-review system, which is all easy to use. Visit http://www.dovepress.com/testimonials.php to read real quotes from published authors.

Submit your manuscript here: http://www.dovepress.com/oncotargets-and-therapy-journal 